cessfully treated with nitroglycerine and nifedipine. Ann Thorac Surg 1983, 36:97-100

5. Briard C, Corat $\mathrm{P}$, Commin $\mathrm{P}$, Chollet A, Menasche $\mathrm{P}$, Echter E: Coronary artery spasm during non-cardiac surgical procedure. Anaesthesia 1983; 38:467-70

6. Buffington CW, Ivey TD: Coronary artery spasm during general anesthesia ANESTHESIOLOGY 1981; 55:466-9

7. Skarvan K, Graedel E, Hasse J, Stulz P, Pfister M: Coronary artery spasm after coronary bypass surgery. ANESTHESIOLOGY 1984; 61:323-7

8. DeWolf AM, Kang YG: Coronary artery spasm and ST-segment depression (letter). Anesthesiology 1985; 62:368

9. Krantz EM, Viljoen JF, Gilbert MS: Printzmetal's variant angina during extradural anaesthesia. Br J Anaesth 1980; 52:945-9

10. Balagot RC, Selim H, Bandelin VR, Kwan BK, Ecanow B: Printzmetal's variant angina in the immediate post-anesthetic state. ANesthesiology 1977; 46 : $355-7$

11. Hoka S, Izumi K, Matsukado T, Matsuda K, Takashadi S: Coronary artery spasm induced under lumbar epidural anesthesia. Eur J Anaesthesiol 1995 6:609-12
12. Yasue H, Yutaka H, Nakamura N, Fujii H, Imoto N, Sonoda R, Kugiyama K, Obata K, Morikami Y, Kimura T: Induction of coronary artery spasm by acetylcholine in patients with variant angina: Possible role of the parasympathetic nervous system in the pathogenesis of coronary artery spasm. Circulation 1986; 74:955-63

13. Baron JF, Payen D, Coriat P, Edouard A, Viars P: Forearm vascular tone and reactivity during lumbar epidural anesthesia. Anest Analg 1988; 67:1065-70

14. Taniguchi M, Kasaba T, Takasaki M: Epidural anesthesia enhances sympathetic activity in the unanesthetized segments in cats. Anest Analg 1997; 84: $391-7$

15. Bugiardini R, Pozzati A, Ottani F, Morgangni GL, Puddu P: Vasotonic angina: A spectrum of ischemic syndromes involving functional abnormalities of the epicardial and microvascular coronary circulation. J Am Coll Cardiol 1993; 22:417-25

16. Fleisher LA, Frank SM, Shir Y, Estefanous M, Kelly S, Raja SN: Cardiac sympathovagal balance and peripheral sympathetic vasoconstriction: Epidural versus general anesthesia. Anest Analg 1994; 79:165-71

\title{
Bilateral Cannulation of Internal Jugular Veins May Worsen Intracranial Hypertension
}

\author{
Nino Stocchetti, M.D., ${ }^{\star}$ Luca Longhi, M.D., † Valerio Valeriani, M.D.†
}

PATIENTS with intracranial hypertension frequently require central venous catheterization. When intracranial elastance is normal, venous drainage from the brain is not usually impaired by jugular bulb cannulation, ${ }^{1}$ and even during bilateral cannulation, no increase in intracranial pressure (ICP) has been reported. ${ }^{2}$ However, when intracerebral compensatory mechanisms are exhausted, large-caliber catheters in the jugular veins may critically restrict venous outflow and cause a substantial increase in ICP.

We describe a patient with intracranial hypertension managed with aggressive medical treatment. We believe that in this patient, a reduction of cerebral venous drainage from bilateral cannulation of the internal jugular vein was probably the cause of an additional severe increase in ICP.

\section{Case Report}

A 22-yr-old woman with a weight of $55 \mathrm{~kg}$ and height of $172 \mathrm{~cm}$ was admitted to the neurosurgical intensive care unit after suffering a head injury in a traffic accident. At admission, the Glasgow Coma Score was 8 , and the computed tomography scan showed a fracture of the left petrous ridge, a small left temporal laceration, and bifrontal contusions. ${ }^{3,4}$ A subdural catheter was placed, and ICP and mean arterial

* Associate Professor, † Staff, Department of Anesthesia and Intensive Care, Milano University

Received from the Department of Anesthesia and Intensive Care, Milano University, Ospedale Maggiore Policlinico, Istituto di Ricovero e Cura a Carattere Scientifico (IRCCS), Milan, Italy. Submitted for publication January 14, 2003 Accepted for publication April 29, 2003. This study has been supported by the current research funding for the year 2001 of the Ospedale Policlinico, IRCCS Milan, Italy.

Address reprint requests to Dr. Stocchetti: Neuroscience ICU, Department of Anesthesia and Intensive Care, Ospedale Policlinico IRCCS, via F. Sforza 35 20122 Milano, Italy. Address electronic mail to: Stocchet@policlinico.mi.it. Individual article reprints may be purchased through the Journal Web site, www.anestheiosology.org. pressure were continuously recorded and stored through an analogdigital converter in a computer for analysis.

Intracranial hypertension was present from the beginning (opening pressure, $30 \mathrm{mmHg}$ ) and was associated with desaturation of the jugular blood (jugular hemoglobin oxygen saturation, 44\%; arteriojugular $\mathrm{O}_{2}$ difference, $7.6 \mathrm{ml} / \mathrm{dl}$ ). Desaturation was corrected by reducing the cerebral metabolic demand by using propofol and fentanyl and increasing the arterial oxygen content with erythrocyte transfusion, aiming at keeping the hemoglobin level in the range of $9-10 \mathrm{~g} / \mathrm{dl} .^{5}$

Intracranial hypertension was treated according to published guidelines. ${ }^{6}$ Because the usual steps failed to control it, barbiturate coma was started. Noradrenaline infusion was necessary to keep a cerebral perfusion pressure above the threshold of $60 \mathrm{mmHg}^{7}$ It is our policy to insert a Swan-Ganz catheter in all patients who require barbiturate coma and vasopressor infusion. Because a 16-gauge catheter (Arrow International, Inc., Reading, PA) had already been retrogradely placed with the tip in the bulb of the right internal jugular vein for jugular hemoglobin oxygen saturation measurement, an 8-French introducer (Arrow International, Inc.) for the Swan-Ganz catheter was inserted in the left internal jugular vein. The patient was paralyzed, and her head and torso were placed in a flat position. The ICP and mean arterial pressure transducers, zeroed at the external meatus, followed the body position change, so that the recording continued with reliable data. The ICP increased during the maneuver and manual hyperventilation was necessary.

The head was slightly rotated for easier anatomic reference, and the left internal jugular vein punctured without problems. At the end of the cannulation, with the head and neck in a neutral position, the ICP increased to $50 \mathrm{mmHg}$. All possible causes (e.g., malpositioning of the head, pneumothorax, respiratory changes, $\mathrm{PaO}_{2}$ and $\mathrm{PaCO}_{2}$ changes, pain, hyperthermia, seizures, and rapid changes in blood pressure) were excluded. We suspected that simultaneous cannulation of the two internal jugular veins, especially with a second large-bore catheter, might have critically reduced cerebral venous drainage. Leaving the Swan-Ganz catheter in place, we withdrew the introducer from the vein; the ICP suddenly decreased to previous values (fig. 1). No other therapeutic maneuvers were active at that moment, so a clear causeeffect relationship was identified.

Barbiturate coma controlled the ICP, and the subsequent clinical course was unremarkable. At discharge from the intensive care unit, the patient could obey simple orders; after 6 months, she had achieved a good recovery. 


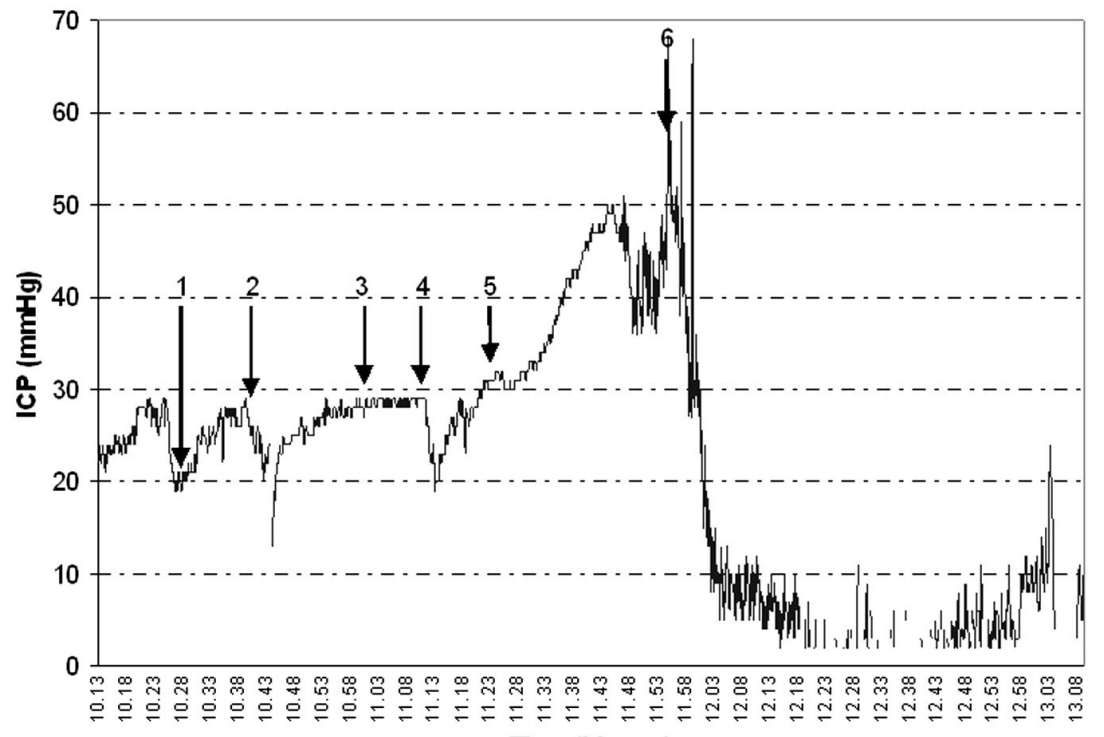

Time (hh.mm)
Figure 1. Intracranial pressure (ICP) after positioning of an 8-French Swan-Ganz introducer in the left jugular vein, with the contralateral jugular internal vein already cannulated. The patient was prepared for the Swan-Ganz insertion (1), and because the ICP was unstable, manual hyperventilation (2), myorelaxant (3), and hyperventilation (4) were used for the control of the ICP. Once the Swan-Ganz introducer was in place (5), the ICP steadily increased until the introducer was removed ( 6 ).

\section{Discussion}

Although the intensive care unit is meant to provide a safe environment, many maneuvers are risky. ${ }^{8}$ Central vein cannulation involves a risk of pneumothorax. ${ }^{9}$ Cannulation of the internal jugular vein toward the mediastinum is routinely preferred because it is not associated with any greater risk than subclavian cannulation ${ }^{10}$ and is widely used for Swan-Ganz catheter insertion. ${ }^{11}$

Venous drainage from the intracranial cavity is mainly through the jugular veins. ${ }^{12}$ Severe reduction of their lumens therefore may impair venous outflow and cause intracranial blood volume to increase. Compression of the jugular vein is, in fact, recognized as a potential cause of intracranial hypertension. ${ }^{13,14}$

Any increase in intracranial volume will be reflected in ICP, depending on the capacity of compensatory mechanisms. Although we did not measure intracranial elastance, we can reasonably assume that this patient was at a steep point in her pressure-volume curve. ICP was greatly increased because of voluminous bifrontal contusions, and her basal cisterns were not visible on the computed tomography scan. At this critical point, even a slight increase in cerebral volume may cause a substantial increase in ICP. However, restoration of the venous drainage rapidly decreased it.

In the literature, we found no reports that ICP may be significantly affected by central vein cannulation, even when bilateral retrograde cannulation of the jugular veins is performed. ${ }^{15}$

In cases with bilateral cannulation, however, the diameters of the catheters were always smaller than the introducer used in this case. When ICP is high and limited buffer capacity of the intracranial system is suspected, maneuvers causing any additional increase in the intracranial volume, such as bilateral cannulation of the internal jugular veins with large-bore catheters, should be avoided.

\section{References}

1. Goetting MG, Preston G: Jugular bulb catheterization does not increase intracranial pressure. Intensive Care Med 1991; 17:195-8

2. Stocchetti N, Paparella A, Bridelli F, Bacchi M, Piazza P, Zuccoli P: Cerebral venous oxygen saturation studied with bilateral samples in the internal jugular veins. Neurosurgery 1994; 34:38-44

3. Marshall LF, Marshall SB, Klauber MR, Clark MvB, Eisenberg HM, Jane JA, Luerssen TG, Marmarou A, Foulkes MA: A new classification of head injury based on computerized tomography. J Neurosurg 1991; 75:S14-20

4. Servadei F, Nanni A, Nasi MT, Zappi D, Vergoni G, Giuliani G, Arista A: Evolving brain lesion in the first 12 hours after head injury: Analysis of 37 comatose patients. Neurosurgery 1995; 37:899-906

5. Gopinath SP, Robertson CS, Contant CF, Hayes C, Feldman Z, Narayan RK, Grossman RG: Jugular venous desaturation and outcome after head injury. J Neurol Neurosurg Psychiatry 1994; 57:717-23

6. Brain Trauma Foundation, AANS Joint Section on Neurotrauma and Critical Care. Guidelines for the management of severe head injury: Critical pathway for the treatment of established intracranial hypertension. J Neurotrauma 2000; 17:537-8

7. Rosner MJ, Rosner SD, Johnson AH: Cerebral perfusion pressure: Management protocol and clinical results. J Neurosurg 1995; 83:949-62

8. Jones PA, Andrews PJD, Migdley S, Anderson SI, Piper IR, Tocher JL, Housley AM, Corrie JA, Slattery J, Dearden NM, Miller JD: Measuring the burden of secondary insults in head-injured patients during intensive care. J Neurosurg Anesthesiol 1994; 1:4-14

9. Shah KB, Rao TL, Laughlin S, El-Etr AA: A review of pulmonary artery catheterization in 6,245 patients. ANESTHESIOLOGY 1984; 61:271-5

10. Mansfield PF, Hohn DC, Fornage BD, Gregurich MA, Ota DM: Complications and failures of subclavian-vein catheterization. N Engl J Med 1994; 331: $1735-8$

11. Damen J, Bolton D: A prospective analysis of 1,400 pulmonary artery catheterizations in patients undergoing cardiac surgery. Acta Anaesthesiol Scand 1986; 30:386-92

12. Hatiboglu MT, Anil A: Structural variations in the jugular foramen of the human skull. J Anat 1992; 180:191-6

13. Hulme A, Cooper R: The effects of head position and jugular vein compression on intracranial pressure, Intracranial Pressure III. Edited by Becks J, Bosch DA, Brock M. New York, Springer-Verlag, 1976, pp 259-63

14. Woda RP, Miner ME, McCandless C, McSweeney TD: The effect of right internal jugular vein cannulation on intracranial pressure. J Neurosurg Anesthesiol 1996; 8:286-92

15. Latronico N, Beindorf AE, Rasulo FA, Febbrari P, Stefini R, Cornali C, Candiani A: Limits of intermittent jugular bulb oxygen saturation monitoring in the management of severe head injury. Neurosurgery 2000; 5:1131-9 